\title{
FORMAÇÃO DO INDIVÍDUO, CONSCIÊNCIA E ALIENAÇÃO: O SER HUMANO NA PSICOLOGIA DE A. N. LEONTIEV
}

\author{
Newton Duarte*
}

RESUMO: Neste artigo são analisados três aspectos da psicologia de A. N. Leontiev e suas implicações para a reflexão sobre a educação na atualidade: a diferença entre a formação do indivíduo humano e a ontogênese animal; a relação entre a estrutura da consciência e a estrutura da atividade; e, por fim, a questão da alienação como um fenômeno social e histórico.

Palavras-chave: Leontiev. Psicologia sócio-histórica. Marxismo. Atividade humana. Consciência. Alienação.

INDIVIDUAL DEVELOPMENT, CONSCIOUSNESS AND ALIENATION: THE HUMAN BEING IN A. N. LEONTYEV'S PSYCHOLOGY

ABSTRACT: In this paper, the implications of Leontyev's psychology on the current educational practices are analyzed highlighting three main areas of focus: human individual development and its differences from animal ontogenesis; the relations between the structure of consciousness and that of activity; and the social and historical phenomenon of alienation.

Key words: Leontyev. Social-historical psychology. Human activity. Consciousness. Alienation

Livre-docente em psicologia da educação, professor do Departamento de Psicologia da Educação da UNESP, campus de Araraquara, e coordenador do Grupo de Pesquisa "Estudos Marxistas em Educação”.E-mail: newton@fclar.unesp.br e newton.duarte@uol.com.br 


\section{Introdução}

leksei Nikolaevich Leontiev ${ }^{1}$ nasceu em 1903 e faleceu em
1979. Portanto, nesse ano de 2003 se comemorou o centená-
rio de nascimento desse psicólogo soviético que, juntamente com Lev Semenovich Vigotski (1896-1934) e Alexander Romanovich Luria (1902-1977), tornou-se referência internacional não para a psicologia, mas também para outras áreas como educação e sociologia.

Neste artigo focalizarei alguns aspectos da psicologia marxista de Alexis N. Leontiev, os quais se constituem, como procurarei mostrar, em significativas contribuições para a educação contemporânea. Dados os inevitáveis limites do que é possível abordar no espaço de um artigo, deixarei de abordar outros aspectos dessa psicologia que também são importantes para a educação, como é o caso do conceito de atividadeguia (ou atividade principal ou atividade dominante), ${ }^{2}$ ao lado de algumas questôes que considero de grande importância no estudo dos trabalhos produzidos pelos integrantes dessa corrente da psicologia soviética. A primeira questão é a das relações entre os trabalhos de Vigotski e os de Leontiev, por mim já abordada em estudos anteriores (Duarte, 1996 e 2000). Minha postura com relação a esse tema não se alterou, ou seja, continuo defendendo a interpretação segundo a qual os trabalhos de Leontiev dão continuidade e desenvolvem a mesma corrente psicológica inaugurada por Vigotski. As divergências que existam entre esses dois autores não caracterizam uma ruptura ou um conflito entre eles: seus trabalhos somam-se, sendo comum a ambos a fundamentação filosófica nas obras de Karl Marx (1818-1893) e Friedrich Engels (1820-1895). A segunda questão que não terei espaço para abordar neste artigo é justamente a das relações entre a concepção filosófica de ser humano contida nas obras de Marx e Engels e a psicologia de Leontiev. Também neste aspecto existem divergências entre os intérpretes contemporâneos, mas analisar essas divergências exige um artigo à parte. Uma terceira questão, estreitamente ligada às duas anteriores, seria a da análise histórica do processo de construção de uma psicologia marxista, ou seja, quais avanços foram alcançados nesse terreno, quais contribuiçóes existem nesse sentido e como estaria esse processo de construção nos dias de hoje.

Devo também registrar logo de início que, ao analisar algumas contribuições da psicologia de Alexis N. Leontiev para a educação 
Formação do indivíduo, consciência e alienação...

contemporânea, não estou, de forma alguma, defendendo uma concepção psicologizante segundo a qual a psicologia seria o fundamento por excelência do pensamento e da prática em educação. Como tenho já explicitado em trabalhos anteriores (Duarte, 1993, 1996, $2000,2003)$, a própria incorporação das contribuições da psicologia à educação requer a mediação de uma teoria pedagógica. Isso significa que há uma teoria pedagógica marxista, ou ao menos um esboço desta, implícita à minha leitura dos trabalhos de Leontiev. Nos meus mencionados trabalhos anteriores tenho procurado explicitar tal pedagogia, bem como tenho feito a crítica a interpretações dos trabalhos dessa corrente da psicologia inspiradas em linhas de pensamento estranhas ao marxismo como, por exemplo, o construtivismo, o escolanovismo ou o pós-modernismo.

Prestados os necessários esclarecimentos preliminares, passemos aos itens que compóem este artigo: no primeiro item focalizarei o ponto de partida de Leontiev: a diferença entre a ontogênese animal e a ontogênese humana, ou seja, a diferença entre formação de um ser humano e a adaptação de um organismo ao meio ambiente; no segundo item abordarei uma questão central em Leontiev, a da relação entre a estrutura da atividade e a estrutura da consciência; no terceiro $e$ último item analisarei a problemática da alienação na obra de Leontiev.

\section{Como se forma um ser humano?}

A resposta à pergunta acima formulada tem como ponto de partida, numa perspectiva marxista, a análise das diferenças entre a atividade humana e a atividade animal, ou seja, a caracterização daquilo que é próprio ao mundo construído historicamente pelos seres humanos. Indagar-se sobre o que diferencia o gênero humano das espécies animais é indagar-se sobre o processo histórico de construção da cultura, pois é por meio dessa construção que o gênero humano vai humanizando o seu mundo e humanizando a si próprio (Markus, 1978). Mas por que tal distinção é importante para uma abordagem marxista? Na verdade o que está aí em questão é a dialética entre necessidade e liberdade nos rumos seja da sociedade humana como um todo seja na vida de cada indivíduo. Ao contrário do que propagam as visões romantizadoras da natureza, nesta não 
há liberdade, há apenas a necessidade, existem apenas os processos causais, espontâneos, imanentes, dos quais está ausente a ação movida por objetivos conscientes.

Marx entendia que o desenvolvimento histórico do gênero humano tem sido um processo contraditório e conflituoso, movido pela luta de classes e pela contradição entre o desenvolvimento das forças produtivas e as relações sociais de produção. Uma das maneiras como pode ser entendido o conceito de liberdade em Marx é justamente a de que o gênero humano constrói sua liberdade à medida que os processos sociais sejam fruto de decisões coletivas e conscientes, diferenciando-se dos processos naturais espontâneos e superando os processos sociais alienados nos quais aquilo que é social, e portanto criado pelos próprios seres humanos, domina estes como se fossem forças naturais incontroláveis tais como um terremoto, um furação, a erupção de um vulcão etc. ${ }^{3}$

Um aspecto central tanto em Marx como em Leontiev é o de que os mesmos processos dialéticos que diferenciam a atividade humana da atividade animal são aqueles que produzem a historicidade do ser humano, isto é, que movem a história humana. Passemos então à análise do que é específico à atividade humana.

Os animais, quando se relacionam com o meio ambiente à sua volta, realizam atividades que resultam na satisfação de suas necessidades. Toda vez a que assistimos na TV algum daqueles programas sobre a vida de espécies animais nos deparamos com um narrador que explica os motivos pelos quais os animais daquela espécie agem daquela forma. As variações que possam existir no comportamento daquele animal em particular que foi filmado são todas elas decorrentes dos esforços daquele ser vivo para se adaptar ao meio ambiente e para sobreviver naquele meio, e para tanto ele se utiliza do conjunto de faculdades que herdou de sua espécie. $\mathrm{Na}$ origem de uma atividade animal, ou seja, seu motivo real, há sempre uma necessidade a ser satisfeita. A atividade é bem-sucedida se a necessidade for satisfeita e é malsucedida se a necessidade permanecer sem ser satisfeita. A atividade animal pode se dar em níveis de complexidade bastante grandes e também pode envolver relações dentro de um coletivo, no caso das espécies gregárias. Os animais podem até chegar a "construir" coisas, como o joão-de-barro e muitas outras espécies de pássaros que cons- 
Formação do indivíduo, consciência e alienação...

troem seus ninhos; como as abelhas que constroem os favos; as formigas que constroem sua habitação coletiva etc. Não é de hoje que a engenhosidade dos animais encanta os seres humanos. Observemos, porém, certos aspectos disso tudo que estou descrevendo. Começando dessa última afirmação, ou seja, que nós, seres humanos, somos capazes de nos encantarmos com a engenhosidade da atividade de certos animais. Mas os animais não se encantam com nossa atividade. Também acima mencionei os programas de TV nos quais biólogos analisam a atividade animal. Mas os animais não analisam a atividade humana. Também mencionei que certos pássaros, como o joão-de-barro, constroem ninhos. Mas há quantos milhares ou milhões de anos o joão-de-barro (ou seja, muito tempo antes de os seres humanos decidirem dar um nome a ele) construía seu ninho praticamente tal como ainda hoje constrói. O ser humano começou a construir habitações muito tempo depois do joão-de-barro e, no entanto, nossas habitações são hoje muitíssimo mais complexas que o ninho desse pássaro. Tudo isso está relacionado com o que diferencia a atividade humana da atividade animal. Passemos então à análise da atividade humana.

Os seres humanos, a partir de um certo ponto da evolução natural (biológica), tornaram-se biologicamente aptos à realização de uma atividade chamada "trabalho". Hoje em dia utilizamos a palavra "trabalho" para nos referirmos ao emprego, à profissão, ou seja, para nos referirmos a um processo de troca próprio da sociedade capitalista: nós trocamos nossa atividade por um salário. Por isso Marx dizia que o operário vende sua força de trabalho, ou seja, que a força de trabalho do operário é, na sociedade capitalista, uma mercadoria. Mas essa forma de trabalho é uma forma historicamente situada, que surgiu juntamente com os demais aspectos essenciais que caracterizam a sociedade capitalista, que é a sociedade que sucedeu ao feudalismo e que existe até hoje. ${ }^{4}$ Já existiram formas históricas diferentes de trabalho e espero que no futuro existam formas diferentes da forma capitalista, isto é, formas não alienadas de trabalho. Mas tanto no passado como no presente e também no futuro há certas características que definem o trabalho como uma atividade humana, fazendo agora abstração das transformações históricas. A primeira dessas características é a de que, ao passo que os animais agem para satisfazer suas necessidades, os seres humanos agem para produzir os meios de satis- 
fação de suas necessidades (Marx \& Engels, 1993, p. 39-40). Isso parece ser apenas um jogo de palavras mas não é. Imaginemos uma situação na qual um grupo primitivo de seres humanos, nossos ancestrais, transformou uma pedra num objeto perfurante ou cortante e então usou esse objeto para caçar e, com o produto da caçada, pôde satisfazer a necessidade de alimento. $\mathrm{O}$ importante aspecto a ser destacado é o de que, entre a necessidade de alimento dada no ponto de partida e a satisfação dessa necessidade no ponto de chegada, há um elemento intermediário, há uma atividade mediadora: a produção de instrumentos. Não importa quão primitivo seja esse primeiro instrumento, a pedra lascada. Importa que começa aí a diferenciação entre o ser humano e os animais.

Essa atividade de produção dos meios de satisfação das necessidades humanas vai acarretar também, ainda segundo Marx \& Engels (idem, ibid.), o surgimento de novas necessidades, de um novo tipo de necessidades, não mais aquelas imediatamente ligadas ao corpo humano como fome, sede etc., mas necessidades ligadas à produção material da vida humana. No exemplo citado, necessidade de se descobrir outros tipos de pedras ou outros tipos de material que possam ser usados na produção de instrumentos de caça. Torna-se necessário conhecer mais a natureza, desenvolver mais as habilidades necessárias à transformação de objetos naturais em objetos sociais. E não nos esqueçamos de algo fundamental: a atividade humana, desde seu início, foi sempre coletiva. No caso da citada atividade de caça, vão surgindo também determinadas maneiras de os seres humanos se organizarem para caçar. Isso quer dizer que além da produção de instrumentos temos também a "produção" de relações sociais. No mesmo processo vai sendo produzida a fala, ou seja, a mais fundamental forma de linguagem humana que é, também ela, algo surgido na atividade coletiva de trabalho. Assim, tanto os instrumentos como as relações entre os integrantes do grupo e também a linguagem foram adquirindo uma existência objetiva, como resultados da atividade humana. Na linguagem de Marx, incorporada por Leontiev, esse processo é denominado "objetivação". Por meio desse processo de objetivação, a atividade física ou mental dos seres humanos transferese para os produtos dessa atividade. Aquilo que antes eram faculdades dos seres humanos se torna, depois do processo de objetivação, características por assim dizer "corporificadas" no produto dessa ativi- 
Formação do indivíduo, consciência e alienação...

dade, o qual, por sua vez, passa a ter uma função específica no interior da prática social. Um objeto cultural, seja ele um objeto material, como por exemplo um utensílio doméstico, seja ele um objeto nãomaterial, como uma palavra, tem uma função social, tem um significado socialmente estabelecido, ou seja, deve ser empregado de uma determinada maneira (o fato de que o objeto cultural tenha, muitas vezes, mais de uma função não altera a regra de que sua existência está necessariamente ligada à prática social). O processo de objetivação é, portanto, o processo de produção e reprodução da cultura humana (cultura material e não-material), produção e reprodução da vida em sociedade.

$\mathrm{O}$ processo de objetivação da cultura humana não existe sem o seu oposto e ao mesmo tempo complemento, que é o processo de apropriação dessa cultura pelos indivíduos. Leontiev foi o psicólogo que melhor estudou e caracterizou a importância do processo de apropriação no campo da psicologia, o que pode ser constatado pela leitura dos trabalhos reunidos no livro $O$ desenvolvimento do psiquismo (Leontiev, 1978b, Leontyev, 1981; Leontiev, s/d.). ${ }^{5}$

Uma das características da apropriação seria, segundo Leontiev, a de que se trata de um processo sempre ativo, isto é, o indivíduo precisa realizar uma atividade que "reproduza os traços essenciais da atividade acumulada no objeto" (Leontiev, 1978b, p. 268). A atividade a ser reproduzida, em seus traços essenciais, pelo indivíduo que se apropria de um produto da história humana é, no mais das vezes, a atividade de utilização desse objeto mas, em certos casos, pode ser necessária também a reprodução da atividade de produção do objeto.

Outra característica do processo de apropriação é a de que, por meio dele, são reproduzidas no indivíduo "as aptidões e funções humanas historicamente formadas" (idem, ibid., p. 169), ou seja, a apropriação da cultura é o processo mediador entre o processo histórico de formação do gênero humano e o processo de formação de cada indivíduo como um ser humano. Para ser exato, devo acrescentar que também o processo de objetivação faz essa mediação, pois não há apropriação da cultura se não tiver ocorrido a objetivação do ser humano nos produtos culturais de sua atividade social. Nos animais a relação entre a espécie e cada ser singular pertencente a ela é determinada pela herança genética. No caso do ser humano a relação en- 
tre os indivíduos e a história social é mediatizada pela apropriação dos fenômenos culturais resultantes da prática social objetivadora.

$\mathrm{Na}$ medida em que a atividade humana se objetiva em produtos culturais, sejam eles materiais ou não, temos, como conseqüência, que o processo de objetivação do gênero humano é cumulativo. Assim, no significado de um objeto ou fenômeno cultural está acumulada a experiência histórica de muitas gerações. Analisemos o exemplo dos instrumentos. Um instrumento é, num determinado sentido, um resultado imediato da atividade de quem o produziu. Neste sentido contém o trabalho objetivado da pessoa ou das pessoas que participaram de sua produção. Mas ele é também atividade humana objetivada num outro sentido, qual seja, como resultado da história de "geraçôes" de instrumentos do mesmo tipo. Durante essa história, o instrumento vai sofrendo transformaçôes e aperfeiçoamentos por exigência da atividade social. Portanto os produtos culturais resultantes do processo de objetivação são sempre sínteses da atividade humana. Daí que, ao se apropriar de um produto cultural, o indivíduo está se relacionando com a história social, ainda que tal relação nunca venha a ser consciente para ele, como é o caso, para a grande maioria das pessoas, da apropriação $\mathrm{da}$ linguagem oral. As pessoas apropriam-se da linguagem desde a infância e, dessa forma, relacionam-se, sem terem consciência disso, com a história de produção, utilização e modificação da linguagem. Tal consciência só surge quando o desenvolvimento sócio-histórico produz a necessidade dos estudos sobre a linguagem (a lingüística). ${ }^{6}$

A terceira característica do processo de apropriação, assinalada por Leontiev (1978b, p. 272), é a de que tal processo é sempre mediatizado pelas relaçôes entre os seres humanos, sendo, portanto, um processo de transmissão de experiência social, isto é, um processo educativo, no sentido lato do termo. O indivíduo forma-se, apropriando-se dos resultados da história social e objetivando-se no interior dessa história, ou seja, sua formação realiza-se por meio da relação entre objetivação e apropriação. Essa relação se efetiva sempre no interior de relaçôes concretas com outros indivíduos, que atuam como mediadores entre ele e o mundo humano, o mundo da atividade humana objetivada. A formação do indivíduo é sempre um processo educativo, podendo este ser direto ou indireto, intencional ou não-intencional, realizado por meio de atividades práticas ou de explanaçôes orais etc. No caso específico da educação escolar, trata-se de um processo 
Formação do indivíduo, consciência e alienação...

educativo direto e intencional (Saviani, 2003), por meio do qual o indivíduo é levado a se apropriar das formas mais desenvolvidas do saber objetivo produzido historicamente pelo gênero humano (Duarte, 1993, 1996, 2003).

Explicada a diferença entre a ontogênese humana e a ontogênese animal em Leontiev, passemos agora ao próximo aspecto central, outro importante ponto na teoria e nas pesquisas psicológicas desenvolvidas por esse autor.

\section{A estrutura da atividade e a estrutura da consciência}

No item anterior mencionei o fato de a atividade humana, desde seus primórdios, ter sido sempre uma atividade que envolve relações objetivas entre o indivíduo e o restante da coletividade da qual ele é parte. Lascar a pedra e usá-la como instrumento de caça não era algo realizado por um indivíduo solitário tal como um Robinson Cruzoe, mas sim uma parte de uma atividade coletiva. Quais as conseqüências, para a consciência humana, desse caráter necessariamente social de nossas atividades? Boa parte de estudos e pesquisas realizados por Leontiev esteve voltada para a busca de respostas a essa questão, como pode ser constatado tanto no livro $O$ desenvolvimento do psiquismo (Leontiev, 1978b; Leontyev, 1981) como no livro Atividade, consciência e personalidade (Leont'ev, 1978a; Leontiev, 1978c). ${ }^{7}$

A estrutura da atividade animal caracteriza-se por uma relação imediata entre $o$ motivo da atividade, ou seja, aquilo que leva o animal a agir, e $o$ objeto da atividade, ou seja, aquilo para o qual se dirige a atividade do animal. Um predador, quando está com fome e vê uma possível presa, age de maneira a abater essa presa e dela se alimentar. $\mathrm{O}$ motivo da atividade, nesse caso, é a necessidade de alimento, motivo esse que está em relação direta com a atividade realizada pelo animal, ou seja, a atividade de perseguir e abater a presa. Dizendo a mesma coisa com outras palavras, existe na atividade animal uma relação direta entre o conteúdo da atividade (o que o animal faz) e o motivo da atividade (por que o animal realiza essa atividade). Do ponto de vista dos processos psicológicos, há uma fusão, na mente do predador, entre a necessidade de alimento e outro animal a ser perseguido e abatido. $\mathrm{Na}$ psicologia animal o objeto não se distingue das necessidades do ser que age sobre esse objeto. 
Diferentemente da atividade animal, na atividade humana deixa de existir essa relação imediata entre o motivo e o objeto da atividade, surgindo uma outra e mais complexa estrutura de atividade, bem como uma outra e mais complexa estrutura psicológica. Para explicar a estrutura da atividade humana Leontiev faz uma diferenciação entre atividade e ação e dá como exemplo a já aqui mencionada atividade coletiva de caça realizada por um primitivo grupo de seres humanos. Essa atividade seria composta de várias ações realizadas por diferentes indivíduos integrantes do grupo. Uma das açôes, como aqui já foi mencionado, seria a de produzir instrumentos para usar na caça. Outra seria acender e preservar o fogo usado para assar a carne do animal. No momento da caçada propriamente dita, o grupo de caçadores dividir-se-ia em dois. O primeiro grupo, constituído pela maioria dos caçadores, ficaria à espreita num lugar previamente estabelecido, no qual seria mais fácil encurralar e abater o animal do que numa situação em campo aberto, na qual o animal a ser caçado (imaginemos que seja um animal ágil e veloz) tem mais chances de escapar. A outra parte do grupo seria constituída por apenas um ou dois integrantes do grupo, que Leontiev chama de batedores. A função do batedor seria a de espantar os animais, mas com um propósito determinado, o de que os animais, ao fugirem dos batedores, corressem inadvertidamente para onde estavam à espreita os demais integrantes do grupo, que se encarregariam de encurralar e abater a caça. O batedor (ou batedores) não precisaria, inclusive, estar munido de instrumentos de caça. Poderia até não ter nada em suas mãos, bastando apenas correr, gritar, enfim, espantar os animais. Essa é a ação do batedor, esse é o conteúdo de sua ação. Se nós víssemos apenas essa ação, pela qual o indivíduo espanta os animais, e tivéssemos conhecimento apenas de que a necessidade (o motivo) que leva o batedor a agir é a fome, a necessidade de se alimentar da carne dos animais que ele acabou de espantar para longe de si, poderíamos concluir que a conduta desse indivíduo é desprovida de sentido, sendo até o oposto do que seria esperado, ou seja, que o indivíduo tentasse abater o animal e satisfazer sua fome. O que dá sentido à atividade desse indivíduo, ou seja, o que conecta sua ação com o motivo dessa ação? A resposta é: as relaçōes sociais existentes entre ele e o restante do grupo ou, em outras palavras, o conjunto da atividade social. Somente como parte desse conjunto é que a ação individual adquire 
Formação do indivíduo, consciência e alienação...

um sentido racional. A mesma coisa podemos dizer com relação às demais ações que compõem a atividade dada como exemplo. Os indivíduos que ficaram escondidos, esperando pelo momento em que os animais viriam ao seu encontro, agiram assim porque sabiam que o batedor espantaria os animais em sua direção. Se assim não fosse, a ação de ficar escondido seria tão desprovida de sentido quanto a ação de espantar os animais. No início do exemplo mencionei que algum indivíduo teria realizado a ação de fazer fogo e preservá-lo aceso. Podemos dizer que há uma relação direta, imediata, entre a ação de acender o fogo e a necessidade que constitui o motivo primeiro dessa ação, que é a fome? Obviamente que não. Acender o fogo não mata a fome. Seria uma relação direta se o indivíduo estivesse com frio e tivesse acendido o fogo para se aquecer. Se a necessidade é a de alimento, o que dá sentido à ação desse indivíduo, o qual não foi participar da caçada propriamente dita, são as relações existentes entre ele e o restante do grupo. Uma ação é, portanto, para Leontiev, um processo no qual não há uma relação direta entre o motivo e o conteúdo (ou objeto) dessa ação. A ação só existe como integrante de um todo maior que é a atividade. A única situação na qual não há distinção entre ação e atividade é aquela na qual a atividade é composta de uma única ação, como no caso do indivíduo que produz fogo para se aquecer. $\mathrm{Na}$ grande maioria das situações, porém, as atividades humanas são constituídas por um complexo conjunto de ações.

Essa relação mediatizada, indireta, entre a ação e o motivo da atividade como um todo precisa ser devidamente traduzida no âmbito subjetivo, ou seja, na consciência dos indivíduos. Se, no exemplo acima apresentado, a consciência do batedor não fosse capaz de estabelecer, com antecipação, o conjunto das ações que compõem essa atividade de caça, é óbvio que o batedor não realizaria adequadamente sua própria ação. E aqui estou me referindo também aos aspectos cognitivos da consciência como aos aspectos efetivos, ou seja, aos sentimentos e às emoçôes. Quando ele vê os animais que poderiam satisfazer sua fome se distanciarem velozmente dele, de maneira que objetivamente ele não poderia alcançá-los e abatê-los, seu estado emocional interior não será o de frustração se os animais se dirigirem para o local no qual os outros seres humanos integrantes do grupo estão à espreita. Na realidade o batedor antecipa em sua subjetividade a sensação eufórica que acompanha a caçada bem-sucedida. Tanto 
em termos cognitivos como em termos afetivos, a estrutura do psiquismo humano diferencia-se da estrutura do psiquismo animal, tal como ocorre com a estrutura objetiva da atividade. $\mathrm{Na}$ mente humana há, portanto, uma relação indireta, mediatizada, entre o conteúdo da ação e o motivo desta. Usando os termos de Leontiev, ao conteúdo da ação, isto é, àquilo que constitui seu objeto, vincula-se o "significado da ação", ou seja, o significado da ação é aquilo que o sujeito faz, é a resposta à pergunta: $\mathrm{O}$ que o indivíduo está fazendo? Mas a consciência humana, segundo Leontiev, trabalha com as relações entre o significado e o sentido da ação. O que seria o sentido da ação? Para Leontiev o sentido da ação é dado por aquilo que liga, na consciência do sujeito, o objeto de sua ação (seu conteúdo) ao motivo dessa ação. No caso do exemplo dado, na subjetividade do batedor o sentido de sua ação é estabelecido pela elaboração mental das conexões objetivamente existentes entre ele e o restante do grupo. É isso que faz com que a visão do animal se distanciando tenha para o batedor o sentido de que em breve ele irá saciar sua fome. Somente as relações sociais podem produzir tal sentido na mente do batedor. Trata-se portanto de um fenômeno essencialmente social. Igual análise aplica-se a todas as demais ações que integram essa caçada coletiva.

Um aspecto que merece ser aqui mencionado mas que não poderei explorar neste artigo é o de que os aspectos afetivo-emocionais do agir humano estão, segundo Leontiev, mais diretamente dependentes do sentido da ação. Isso quer dizer que uma mesma ação pode vir acompanhada de diferentes emoções e sentimentos, dependendo de qual seja a atividade que constitui a totalidade que dá sentido a essa ação.

Essa análise da relação entre significado e sentido das ações humanas tem decisivas implicações para a educação. Um dos grandes desafios da educação escolar contemporânea não seria justamente o de fazer com que a aprendizagem dos conteúdos escolares possua sentido para os alunos? Uma das armadilhas contida nas proposiçóes de boa parte das correntes pedagógicas em voga não seria justamente a de postular uma relação imediatista e pragmática entre o significado e o sentido da aprendizagem dos conteúdos escolares, atrelando essa aprendizagem ao utilitarismo tão forte no alienante cotidiano da sociedade capitalista contemporânea? A reflexão sobre essas perguntas requer a incorporação da análise que Leontiev faz do processo de alie- 
Formação do indivíduo, consciência e alienação...

nação na sociedade capitalista, como um processo que ocorre de duas maneiras: pela dissociação entre o significado e o sentido das ações humanas e pela impossibilidade existente, para a grande maioria dos seres humanos, de apropriação das grandes riquezas materiais e nãomateriais já existentes socialmente. Esse é o tema do próximo item deste artigo.

\section{A alienação como um fenômeno social e histórico}

Ao analisar o processo histórico de desenvolvimento da consciência humana, Leontiev (1978b, p. 89-142) mostra que a divisão social do trabalho e a propriedade privada produziram historicamente uma determinada forma de estruturação da consciência humana, forma essa que se caracteriza pela dissociação entre o significado e o sentido da ação. Leontiev (idem, ibid., p. 123) exemplifica essa dissociação por uma situação de trabalho numa tecelagem:

A tecelagem tem (...) para o operário a significação objetiva de tecelagem, a fiação, de fiação. Todavia não é por aí que se caracteriza sua consciência, mas pela relação que existe entre estas significações e o sentido pessoal que têm para ela as suas açôes de trabalho. Sabemos que o sentido depende do motivo. Por consequiência, o sentido da tecelagem ou da fiação para o operário é determinado por aquilo que o incita a tecer ou a fiar. Mas são tais as suas condições de existência que ele não fia ou não tece para corresponder às necessidades da sociedade em fio ou em tecido, mas unicamente pelo salário; é o salário que confere ao fio e ao tecido o seu sentido para o operário que os produziu (...). Com efeito, para o capitalista, o sentido da fiação ou da tecelagem reside no lucro que dela tira, isto é, uma coisa estranha às propriedades do fruto da produção e à sua significação objetiva.

Como Leontiev usou a expressão "sentido pessoal" convém desfazer desde já possíveis equívocos, especialmente levando-se em conta o idealismo subjetivista que tão largamente se encontra difundido no campo da psicologia. O sentido pessoal que tem a ação de tecer para o operário no exemplo de Leontiev não é algo que o operário possa mudar por meio apenas de um esforço interior para encarar as coisas de um modo diferente. É muito comum entre psicólogos o jargão segundo o qual "nós não podemos mudar o mundo mas podemos mudar nossa atitude para com ele". Quando Leontiev se refere ao sentido pessoal do trabalho do operário ele certamente não tem em vista 
esse tipo de concepção subjetivista. No exemplo apresentado o sentido pessoal é produzido pelas condições objetivas de vida do operário, que o levam a vender a sua força de trabalho em troca de salário. Por essa razão, o sentido do trabalho do operário será para ele o mesmo, esteja ele trabalhando em uma fábrica de tecidos, ou em uma fábrica de armas ou em uma fábrica de remédios que salvam vidas, pois o sentido de seu trabalho é determinado pelo quanto ele recebe e não pelo que ele produz. O sentido do trabalho do operário poderá porém mudar, ainda que parcialmente, numa situação de organização coletiva com vistas à luta contra a exploração do trabalho, luta essa que tenha por horizonte a própria superação das relações sociais capitalitas, a própria superação da lógica de reprodução do capital.

Também para o capitalista o sentido da atividade é dado pelo, digamos, "retorno financeiro" da atividade, o qual, neste caso, não é o salário, mas o aumento do capital. De qualquer forma, assim como ocorre para o operário, não é a utilidade social daquilo que é fabricado que confere sentido à atividade empresarial. A indústria de armas não é movida pela "maldade" de pessoas que não se preocupam com as vidas que serão tiradas com as armas produzidas, assim como a indústria farmacêutica está longe de ser movida pela "bondade" das pessoas preocupadas com as vidas que poderão ser salvas com os remédios produzidos. A atividade produtiva na sociedade capitalista é essencialmente movida pela lógica econômica de reprodução do capital. É isso que determina o sentido dessa atividade.

Nesse ponto farei algumas consideraçôes que estão apoiadas em Leontiev mas que não podem ser a ele atribuídas e, de certa forma, não deixam de apresentar uma modificação no esquema de análise por ele proposto. Faço questão de explicitar minha responsabilidade sobre essas considerações pois não é raro, na história de difusão das idéias dessa corrente da psicologia soviética, que as pessoas atribuam a Vigotski, Leontiev ou Luria idéias que em absoluto foram defendidas por esses autores. O que tenho aqui a apresentar é o seguinte: eu entendo que não se trata de uma oposição entre o sentido pessoal que a atividade de trabalho tem para o próprio operário e o significado social dessa atividade. Penso que tanto para o indivíduo como para a sociedade ocorre essa ruptura entre o significado e o sentido da ação. Se considerarmos o significado como sendo o conteúdo da ação e o sentido como sendo as ligações entre esse conteúdo e o conjunto da 
Formação do indivíduo, consciência e alienação...

atividade, a primeira cisão que aparece é de fato, como analisou Leontiev, aquela entre o conteúdo da ação do operário e o sentido que essa ação tem para o próprio operário. Acontece que também para a sociedade o trabalho do operário apresenta uma cisão entre o conteúdo e o sentido. Como estamos falando de uma sociedade capitalista, o sentido que a atividade do operário tem é o de parte necessária do processo de reprodução do capital, ou seja, o sentido é dado pelo valor de troca da força de trabalho. Como se sabe, na análise formulada por Marx, o valor de troca é indiferente ao valor de uso da mercadoria. No caso dessa mercadoria específica, a força de trabalho, o seu valor de troca é indiferente ao trabalho concreto, ou seja, ao conteúdo da ação concreta do operário. Portanto não é apenas para o operário que o sentido do seu trabalho se dissocia do conteúdo deste, também para a sociedade esse fenômeno ocorre. $\mathrm{Na}$ verdade, o sentido pessoal que o trabalho tem para o operário é uma conseqüência do sentido que esse trabalho tem para a sociedade capitalista. No caso da sociedade essa dissociação entre o conteúdo do que é produzido e o sentido que tem a produção se reflete na separação e muitas vezes no conflito entre a chamada esfera econômica e as demais esferas da vida social. Quando, por exemplo, o governo de um país festeja o reaquecimento da indústria automobilística, o que está sendo considerado é apenas o efeito desse reaquecimento sobre a economia nacional, a "geração de empregos" etc. Mas isso pode estar em absoluto conflito com outras esferas que também ocupam a atenção (ou ao menos deveriam ocupar) dos governantes, como a questão do trânsito que se torna mais difícil e mais perigoso com o aumento do número de veículos em circulação, o provável aumento dos acidentes de trânsito, o aumento da poluição etc. Tudo isso está relacionado ao significado do aumento da produção de veículos automotores. Então o que o governo de um país festeja, nesse caso, é o sentido desse aumento, sentido esse que é dado pela lógica econômica capitalista. Imaginese, por exemplo, que a indústria tabagista de um país alcançasse um crescimento sem precedentes num curto espaço de tempo, principalmente decorrente do aumento explosivo do consumo interno do produto dessa indústria. Isso aqueceria a economia, geraria empregos, aumentaria a arrecadação de impostos, faria esse país fictício sair de uma situação econômica recessiva. Do ponto de vista do sentido que essa atividade tem para a economia capitalista, trata-se, sem dúvida, de 
algo a ser comemorado. Mas as conseqüências disso em termos da saúde da população seriam determinadas pelo significado, isto é, pelo conteúdo daquilo que é produzido por esse ramo da indústria. Há um nítido conflito, uma nítida separação, no plano social, entre o significado e o sentido desse fenômeno.

Do ponto de vista da sociedade como um todo, essa ruptura entre e o significado e o sentido das ações humanas atinge níveis absolutamente destrutivos na sociedade capitalista contemporânea. $\mathrm{Na}$ verdade esse processo social de alienação poderá levar a catástrofes sociais e ambientais sem precedentes na história humana se não houver uma mudança radical na lógica do metabolismo social, como mostrou István Mészàros nos livros Para além do capital (Mészàros, 2002) e $O$ século XXI: socialismo ou barbárie? (Mészàros, 2003).

No que se refere aos processos psicológicos, a ruptura entre o sentido e o significado das ações humanas tem como uma de suas conseqüências o cerceamento do processo de desenvolvimento da personalidade humana. Isso ocorre porque o indivíduo, por vender sua força de trabalho e, em decorrência disso, ter o sentido de sua atividade como algo dissociado do conteúdo dessa atividade, acaba distanciando o núcleo de sua personalidade da atividade de trabalho. $\mathrm{O}$ trabalho torna-se algo externo e estranho à personalidade do indivíduo quando, na realidade, deveria a atividade centrar-se em termos do processo de objetivação da personalidade do indivíduo. ${ }^{8}$ Sem a possibilidade dessa objetivação, a personalidade fica restrita, limitada em seu desenvolvimento. Igualmente o indivíduo não tem na atividade de trabalho, com raras exceçôes, algo que o impulsione a se apropriar de conhecimentos, habilidades e valores que o enriqueçam como ser humano. Foge aos limites deste artigo analisar todas as implicações desse processo altamente alienante e profundamente desumano. Deixo apenas registrado que considero ser esse um tema fundamental para nós, educadores, que trabalhamos com a formação das novas gerações numa sociedade que retira das pessoas a própria possibilidade de elas crescerem como indivíduos por meio de seu trabalho.

Por fim, e já encaminhando para a conclusão do artigo, outra forma na qual aparece a temática da alienação nos trabalhos de Leontiev é a da criação de obstáculos, por parte da sociedade capitalista, à apropriação da cultura humana pelos indivíduos ou, dizendo a mesma coisa com outras palavras, trata-se da apropriação privada da cultura ma- 
Formação do indivíduo, consciência e alienação...

terial e intelectual produzida coletivamente e que deveria constituir-se em patrimônio de todos os seres. Entretanto, dado o regime de acumulação capitalista, indivíduos, classes, grupos e nações inteiras vêemse impossibilitados de se apropriarem dessa cultura, o que produz as desigualdades entre os seres humanos. Leontiev rejeita energicamente qualquer tentativa de se atribuir a fatores biológicos as profundas diferenças produzidas pelas condiçóes sociais de vida das pessoas. Ainda hoje não faltam pesquisadores e ideólogos de todo tipo tentando explicar as diferenças sociais como sendo conseqüência de processos biológicos internos aos indivíduos (herança genética, processos neurofisiológicos, hormônios etc.). Em termos de educação escolar, por exemplo, são bastante recorrentes as mais diversas formas de explicar a trajetória escolar dos indivíduos por referência a fatores primariamente orgânicos. Sem desconsiderar a necessidade do avanço do conhecimento sobre o nosso próprio organismo e sem desconsiderar a necessária base orgânica dos processos psicológicos, Leontiev afirmava que não existem indivíduos biologicamente predispostos ou não-predispostos à atividade artística ou científica ou outra qualquer, mas sim o contrário, que a apropriação da obras artísticas, científicas etc. é que cria nos indivíduos o talento correspondente àquele campo da atividade humana. Por certo essa é uma apaixonada e mais do que nunca atual defesa do papel da educação em geral e em especial da educação escolar na formação dos seres humanos. Se a obra científica de Leontiev não contivesse contribuiçóes para os estudos e as pesquisas educacionais (e espero ter mostrado, no que estava ao meu alcance no espaço de um artigo, que essas contribuiçôes existem e são muito significativas), ainda assim nós, educadores, já estaríamos nos enriquecendo bastante se nos inspirássemos por esse entusiasmo que Leontiev nutria com relação à educação das novas geraçôes.

Recebido em novembro de 2003 e aprovado em março de 2004.

\section{Notas}

1. Como se sabe, o idioma russo utiliza-se de um alfabeto distinto do alfabeto ocidental. A escrita de nomes russos com o alfabeto ocidental apresenta um problema de não-adoção de um mesmo padrão. No caso do autor analisado neste artigo, seu nome tem sido escrito, em ediçōes em língua portuguesa e espanhola, com a letra "i": Leontiev. Entretanto, em ediçōes em inglês o mesmo nome aparece escrito com "y": Leontyev ou com apóstrofo: 
Leont'ev. Adotarei a escrita com a letra “i”, mas preservarei as diferentes grafias quando fizer referência às edições em inglês.

2. Sobre esse conceito veja-se neste número dos Cadernos Cedes o artigo de Marilda G. D. Facci. Sobre a utilização desse conceito para análise do papel da brincadeira na educação da criança em idade pré-escolar, vide também, neste número dos Cadernos Cedes, o artigo de Alessandra Arce.

3. Diga-se de passagem que a naturalização de processos sociais em sua essência é bastante comum no campo da psicologia, como mostra o artigo de Ana Bock neste número dos $\mathrm{Ca}$ dernos Cedes.

4. A despeito de não faltarem autores que afirmam estarmos hoje numa sociedade que não seria capitalista, mas sim sociedade pós-industrial, sociedade do conhecimento, sociedade pósmoderna etc., eu me posiciono ao lado de outros autores, em sua grande maioria marxistas, os quais afirmam que, embora o capitalismo tenha passado por inegáveis mudanças desde o século XIX até este início de século XXI, a reprodução do capital continua a ser o processo determinante da vida social, ou seja, continuamos a viver numa sociedade capitalista.

5. Esse livro é, na verdade, uma coletânea de trabalhos produzidos por Leontiev ao longo de sua carreira científica. Há uma diferença no que se refere a quais textos constam da edição em português e da edição em inglês, na qual o título do livro é Problems of the development of the mind (Leontyev, 1981). Essa edição em inglês contém dois trabalhos de Leontiev ainda não publicados em português: um deles (Leontyev, 1981, p. 7-131) intitula-se "O problema da origem das sensaçōes" (The problem of the origin of sensation), sendo uma parte da tese de doutorado de Leontiev, datada de 1940; o outro trabalho (idem, p. 327-365) intitula-se "O desenvolvimento de formas superiores de memória" (The development of higher forms of memory), sendo um capítulo de um trabalho publicado pela primeira vez em 1931, resultante de uma pesquisa experimental realizada de 1928 a 1930, articulada aos estudos que Vigotski realiza na época, sobre o caráter culturalmente mediatizado dos processos psicológicos superiores. Além desses dois capítulos ainda não publicados em português, a citada edição desse livro de Leontiev contém dois artigos que não constam da edição em português desse livro mas que já foram publicados em português numa coletânea intitulada Linguagem, desenvolvimento e aprendizagem (Vigotski, Luria \& Leontiev, 1988). Um desses artigos (Leontyev, 1981, p. 366-390) se intitula "Os princípios psicológicos da brincadeira pré-escolar" (The psychological principles of preschool play), tendo sido publicado pela primeira vez em 1944; o outro artigo (Leontyev, 1981 p. 391-416) intitula-se "Uma contribuição à teoria do desenvolvimento do psiquismo da criança" (A contribution to the theory of the development of the child's psyche), tendo sido publicado pela primeira vez em 1945 , incorporando idéias que o autor defendera em outros dois trabalhos, publicados em 1938 e 1941. Por sua vez, a edição em português conta com um texto ausente da edição em inglês, intitulado "O homem e a cultura" (Leontiev, 1978b, p. 261-284).

6. Não poderei abordar neste artigo, por fugir ao seu tema, a diferença, estabelecida por Agnes Heller $(1984,1994)$ em sua teoria da vida cotidiana, entre a apropriação das "objetivações genéricas em si" (linguagem, costumes e objetos) e a apropriação das "objetivações genéricas para si” (ciência, filosofia, arte, moral e política). Essa questão já foi por mim abordada em trabalhos anteriores (Duarte, 1993 e 1996). O artigo de João H. Rossler, neste número dos Cadernos Cedes, também aborda as aproximações e afinidades entre a teoria da vida cotidiana de Agnes Heller e a psicologia de Leontiev.

7. Publicado pela primeira vez em russo, em 1975, o livro Atividade, consciência e personalidade foi traduzido e publicado em inglês e espanhol poucos anos depois (Leont'ev,

Cad. Cedes, Campinas, vol. 24, n. 62, p. 44-63, abril 2004

Disponível em <http://www.cedes.unicamp.br> 
Formação do indivíduo, consciência e alienação...

1978a e Leontiev, 1978c, respectivamente). Até o ano de 2003 não havia uma edição em português desse livro, mas no momento em que eu concluía a redação deste artigo fui informado de que está em preparação uma edição brasileira dessa obra, a qual espero já ter sido lançada quando da publicação deste artigo.

8. Sobre a questão da personalidade na psicologia de Leontiev, veja-se neste número dos $\mathrm{Ca}$ dernos Cedes o artigo de Lígia M. Martins.

\section{Referências bibliográficas}

DUARTE, N. A individualidade para-si: contribuição a uma teoria histórico-social da formação do indivíduo. Campinas: Autores Associados, 1993.

DUARTE, N. Educaçâo escolar, teoria do cotidiano e a escola de Vigotski. Campinas: Autores Associados, 1996.

DUARTE, N. Vigotski e o "aprender a aprender": crítica às apropriações neoliberais e pós-modernas da teoria vigotskiana. Campinas: Autores Associados, 2000.

DUARTE, N. Sociedade do conhecimento ou sociedade das ilusões?: quatro ensaios crítico-dialéticos em filosofia da educação. Campinas: Autores Associados, 2003.

HELLER, A. Everyday life. London: Routledge, 1984.

HELLER, A. Sociología de la vida cotidiana. 4. ed. Barcelona: Península, 1994.

LEONT'EV, A.N. Activity, consciousness and personality. Englewood Cliffs, N.J.: Prentice-Hall, 1978a.

LEONTIEV, A.N. O desenvolvimento do psiquismo. Lisboa: Livros Horizonte, $1978 \mathrm{~b}$.

LEONTIEV, A.N. Actividad, conciencia y personalidad. Buenos Aires: Ciencias del Hombre, 1978c.

LEONTIEV, A.N. O desenvolvimento do psiquismo. São Paulo: Moraes, [19-]

LEONTYEV, A.N. Problems of the development of the mind. Moscou: Progresso, 1981 
MARKUS, G. Marxism and anthropology. Assen: Van Gorcum, 1978. MARX, K.; ENGELS, F. A ideologia alemã (Feuerbach). 9. ed. São Paulo: HUCITEC, 1993.

MÉSZÀROS, I. Para além do capital. São Paulo: Boitempo, 2002.

MÉSZÀROS, I. O século XXI: socialismo ou barbárie? São Paulo: Boitempo, 2003.

SAVIANI, D. Pedagogia histórico-crítica: primeiras aproximaçōes. 8. ed. Campinas: Autores Associados, 2003.

VIGOTSKI, L.S.; LURIA, A.R.; LEONTIEV, A.N. Linguagem, desenvolvimento e aprendizagem. São Paulo: Ícone; EDUsP, 1988. 